\title{
Uma espécie nova de Postanomus Funkhouser (Homoptera, Membracidae, Centronodinae) ${ }^{1}$
}

\author{
Randal Lopes Barreira ${ }^{2}$ \\ Albino Morimasa Sakakibara ${ }^{3}$
}

\begin{abstract}
A new species of the genus Postanomus Funkhouser, 1950 (Homoptera, Membracidae, Centronodinae). Postanomus maculatus sp. n., from Brazil, Paraná, is described and illustrated.

KEY WORDS. Homoptera, Membracidae, Centronodinae, Postanomus, taxonomy
\end{abstract}

O gênero atualmente designado Postanomus, foi originalmente descrito por FAIRMAIRE (1846), com o nome de Anomus tendo como espécie tipo A. reticulatus. STÅL (1862) descreveu mais uma espécie para este gênero: A. cornutulus. KIRKALDY (1904) atribuiu-lhe um novo nome Eteoneus, devido Anomus estar preocupado. FUNKHOUSER (1950), descobriu que o nome Eteoneus também já tinha sido usado por Distant (1903) para designar um novo gênero de Tingidae. Propôs então Postanomus.

SAKAKIBARA (1974) revisou o gênero Postanomus e descreveu mais duas espécies: P. ferrugineus Sakakibara, 1974 e P. fuscus Sakakibara, 1974. Acrescenta-se, no presente trabalho, mais uma espécie, $P$. maculatus sp. n., coletada em São José dos Pinhais, município próximo de Curitiba, Paraná. Apresenta-se a chave para as espécies fornecida por SAKAKIBARA (1974), com uma pequena modificação a fim de incluir a espécie nova.

\section{Chave para as espécies}

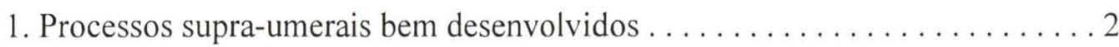

- Processos supra-umerais pouco desenvolvidos . ................ 3

2. Processo supra-umerais cônicos; a distância entre seus ápices igual a duas vezes a largura interocular . . . . . . . . . . . . . . . . . P. cornutulus (Stål)

- Processo supra-umerais com a parte superior levemente achatada e a distância entre seus ápices pouco mais de uma vez e meia a largura interocular . . . . . . P. ferrugineus Sakakibara

3. Pronoto inteiramente fusco ................... f. fiscus Sakakibara

- Pronoto amarelado ou então, castanho com manchas escuras . . . . . . . . . 4

1) Contribuição número 1240 do Departamento de Zoologia, Universidade Federal do Paraná.

2) Curso de Pós-Graduação em Entomologia, Universidade Federal do Paraná. Bolsista da CAPES.

3) Departamento de Zoologia, Universidade Federal do Paraná. Caixa Postal 19020, 81531-990 Curitiba, Paraná, Brasil. Bolsista do CNPq. 
4. Pronoto amarelado; tórax e pernas castanho-claros ... P. reticulatus (Fairmaire)

- Pronoto castanho com manchas escuras; tórax castanho-claro com manchas negras, pernas castanho-escuras . .............. . maculatus $\mathbf{s p .} \mathbf{n}$.

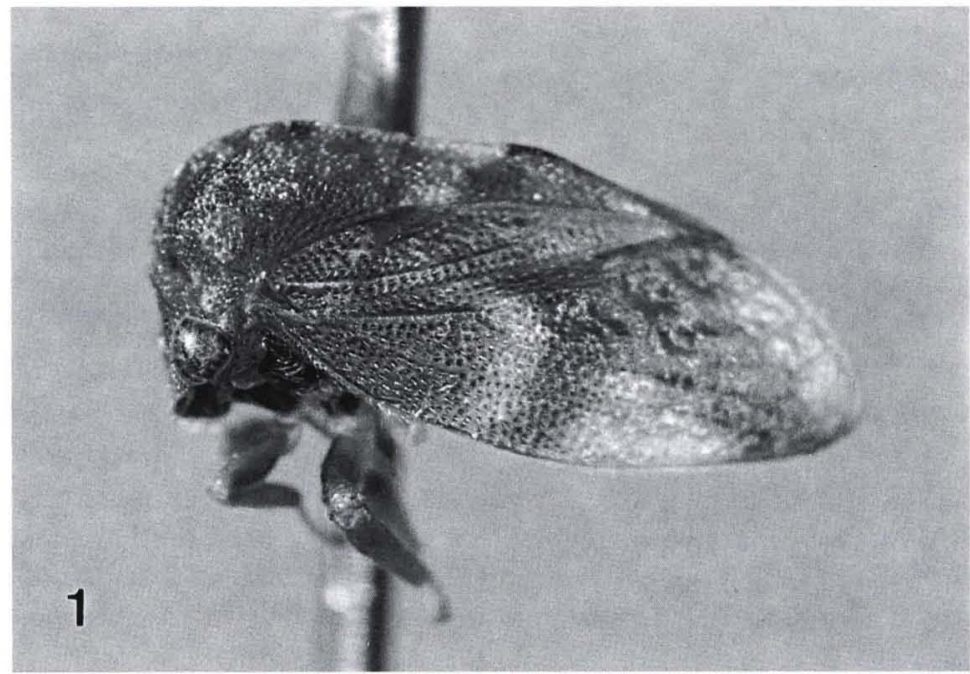

Fig. 1. Postanomus maculatus sp. n., holótipo.

\section{Postanomus maculatus sp. $\mathbf{n}$.}

Figs 1, 2-6

Diagnose. Cabeça e pronoto homogeneamente pontuados, de coloração geral castanho-clara com máculas e listas castanho-escuras; clípeo terminando no mesmo nível das margens dos lóbulos supra-antenais; processos supra-umerais curtos, com ápices castanho-escuros.

Medidas (mm). Macho. Comprimento total: 4,52; comprimento do pronoto: 3,36; largura da cabeça: 1,60; comprimento da cabeça: 0,88 ; largura entre os ângulos umerais: 1,76; distância entre os ápices dos processos supra - umerais: 4,17; comprimento dos processos supra umerais: 0,20 ; comprimento das tégminas: 3,80 ; comprimento das asas: 3,48 .

Descrição. Holótipo macho. Cabeça duas vezes mais larga que longa, homogeneamente pontuada, de forma sub-quadrangular, de coloração castanho-clara, com duas máculas castanho-escuras próximas da margem superior; espaços interocelar e ocelo-oculares planos; ocelos amarelados, situados sobre a linha imaginária que passa pelo centro dos olhos, eqüidistantes destes e entre si; olhos castanho-avermelhados com manchas negras; sutura coronal atingindo a base do clípeo; este alongado com o bordo inferior no mesmo nível das margens dos lóbulos supra-antenais; margem superior do vértice arqueada. Pronoto com o mesmo padrão 

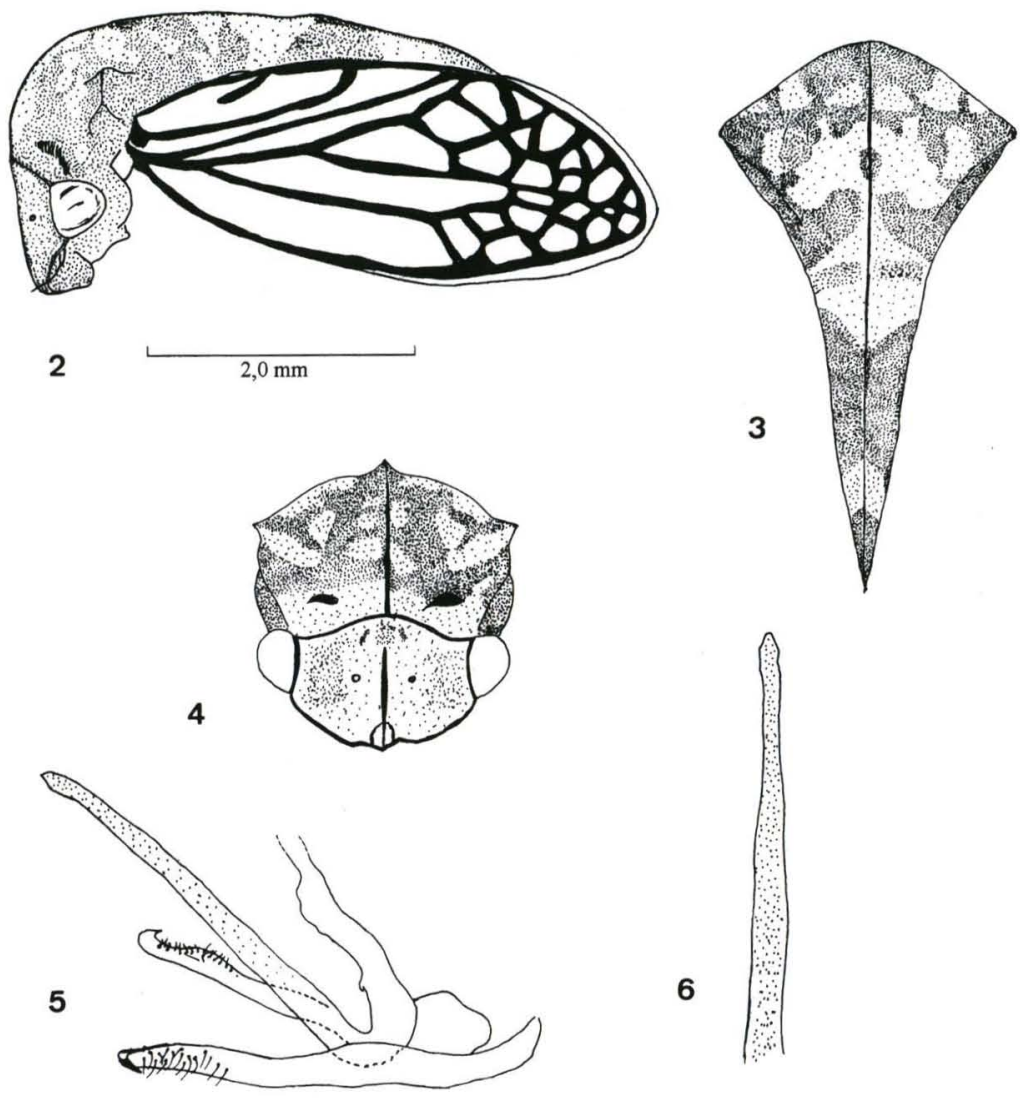

$0,25 \mathrm{~mm}$

Figs 2-6. Postanomus maculatus sp. n. (2) Cabeça, pronoto e tégmina; (3) pronoto, vista dorsal; (4) cabeça e pronoto, vista frontal; (5) parâmeros, edeago e conectivo, vista lateral; (6) ápice do edeago, vista dorsal.

de coloração e pontuação da cabeça, com máculas escuras na parte dorsal; carena dorsal saliente; lóbulos pós-oculares com superfície rugosa; sutura coronal bem evidente; distância entre os ângulos umerais menor que a largura entre os ápices dos processos supra-umerais; processos supra-umerais curtos, pouco evidentes, com os ápices castanho-escuros, cônicos, dirigidos para os lados e levemente para cima; dorso praticamente reto; escutelo parcialmente visível lateralmente. Tégminas com a parte basal coriácea, com o mesmo padrão de coloração do pronoto; parte distal enfumaçada, translúcida. Tórax castanho, com máculas castanho-escuras.. Asas hialinas com venação castanho-clara. Genitália do macho: edeago cilíndrico alongado, com microdenticulações na parte mediana, falobase pouco mais larga que o edeago e de forma cilíndrica; parâmeros mais ou menos cilíndricos, terminados em ganchos curtos. 
Fêmea. Desconhecida.

Material examinado. Holótipo macho com os seguintes dados "Br 277-Km 60, S. J. dos Pinhais [Brasil, Paraná] 14:I: 1977, Z. Buzzi leg.”. (DZUP).

Etimologia. $\mathrm{O}$ nome da espécie é alusivo à presença de manchas escuras no pronoto.

Comentários. Esta espécie é muito parecida com $P$. reticulatus no seu aspecto geral. Difere por apresentar os processos supra-umerais mais curtos e manchas escuras sobre o dorso bem mais destacadas.

\section{REFERÊNCIAS BIBLIOGRÁFICAS}

Distant, W.L. 1903. Rhynchotal notes xix. III. Rhynchota of Sokotra. Ann. Mag. Nat. Hist. 12: 469-480.

Fairmaire, L.M.H. 1846. Revue de la tribu des Membracides. Ann. Soc. Entomol. France 4: 235-320, 479-528.

FUnKHOUSER, W.D. 1950. Family Membracidae. Genera Insectorum 208:1-383.

KIRKALDY, G.W. 1904. Bibliographical and nomenclatorial notes on the Hemiptera, n.3. Entomologist 37:279-283.

Sakakibara, A.M. 1974. As espécies do gênero Postanomus Funkhouser, 1950 (Homoptera, Membracidae). Rev. Brasil. Biol. 34 (3): 345-352.

STÅL, C. 1862. Bidrag till Rio-Janeiro Traktens Hemipter-Fauna. Öfvers. Kongliga Svens. Vetensk. Akad.-Forh. 3:1-75.

Recebido em 14.XI.2000; aceito em 27.VI.2001. 